52. Yoshimoto, T. \& Paul, W. E. CD4 $4^{+}, \mathrm{NK} 1.1^{+}$T cells promptly produce interleukin 4 in response to in vivo challenge with anti-CD3. J. Exp. Med. 179, 1285-1295 (1994).

53. Plaut, M. et al. Mast cell lines produce lymphokines in response to cross-linkage of $\mathrm{F}_{\mathrm{C} \varepsilon} \mathrm{Rl}$ or to calcium ionophores. Nature 339, 64-67 (1989).

54. Seder, R. A. et al. Mouse splenic and bone marrow cell populations that express high-affinity $F_{c \varepsilon}$ receptors and produce interleukin 4 are highly enriched in basophils. produce interleukin 4 are highly enriched in basoph

55. Schmitz, J. et al. Induction of interleukin 4 (IL-4) expression in Thelper $\left(T_{H}\right)$ cells is not dependent on IL-4 from non-T ${ }_{H}$ cells. J. Exp. Med. 179, 1349-1353 (1994).

56. Launois, P. et al. IL-4 rapidly produced by $\mathrm{V} \beta 4 \mathrm{~V} \alpha 8 \mathrm{CD} 4$ $T$ cells instructs $T_{H} 2$ development and susceptibility to Leishmania major in BALB/c mice. Immunity 6, 541-549 (1997).

57. Jacobson, N. G. et al. Interleukin 12 signaling in Thelper type $1\left(T_{1} 1\right)$ cells involves tyrosine phosphorylation of signal transducer and activator of transcription (Stat)3 and Stat4. J. Exp. Med. 181, 1755-1762 (1995).

58. Szabo, S. J. et al. A novel transcription factor, T-bet, directs $\mathrm{T}_{H} 1$ lineage commitment. Cell 100, 655-669 (2000)

59. Kaplan, M. H., Schindler, U., Smiley, S. T. \& Grusby, M. J. Stat6 is required for mediating responses to IL-4 and for development of T 2 cells. Immunity 4, 313-319 (1996).

60. Takeda, K. et al. Essential role of Stat6 in IL-4 signalling Nature $\mathbf{3 8 0}$, 627-630 (1996).

61. Shimoda, K. et al. Lack of IL-4-induced $\mathrm{T}_{H} 2$ response and IgE class switching in mice with disrupted Stat6 gene. Nature 380, 630-633 (1996).

62. Zheng, W. \& Flavell, R. A. The transcription factor GATA-3 is necessary and sufficient for $\mathrm{T}_{H} 2$ cytokine gene expression in CD4 T cells. Cell 89, 587-596 (1997).

63. Zhang, D. H., Cohn, L., Ray, P., Bottomly, K. \& Ray, A. Transcription factor GATA-3 is differentially expressed in murine $T_{H} 1$ and $T_{H} 2$ cells and controls $T_{H} 2$-specific murine $T_{H} 1$ and $T_{H} 2$ cells and controls $T_{H} 2$-specific
expression of the interleukin-5 gene. J. Biol. Chem. 272, expression of the interl

64. Ho, I. C., Hodge, M. R., Rooney, J. W. \& Glimcher, L. H. The proto-oncogene c-maf is responsible for tissuespecific expression of interleukin-4. Cel/ 85, 973-983 (1996)

65. Howard, J. G., Hale, C. \& Liew, F. Y. Immunological regulation of experimental cutaneous leishmaniasis. IV. Prophylactic effect of sublethal irradiation as a result of abrogation of suppressor $T$ cell generation in mice of abrogation of suppressor T cell generation in mice genetically suscepthie to Lesth

66. Scott, P. Natovitz, P. Coffman, R. L., Pearce, E. \& Sher, A. Immunoregulation of cutaneous leishmaniasis. T cell lines that transfer protective immunity or exacerbation belong to different $T$ helper subsets and respond to distinct parasite antigens. J. Exp. Med. 168, 1675-1684 (1988).

67. Heinzel, F. P., Sadick, M. D., Holaday, B. J., Coffman, R. L. \& Locksley, R. M. Reciprocal expression of interferon $\gamma$ or interleukin 4 during the resolution or expansion of distinct helper T cell subsets. J. Exp. Med. expansion of distinct

68. Yamamura, M. et al. Defining protective responses to pathogens: cytokine profiles in leprosy lesions. Science 254, 277-279 (1991).

69. Korenaga, M. et al. The role of interleukin- 5 in protective immunity to Strongyloides venezuelensis infection in mice. Immunology 72, 502-507 (1991)

70. Urban, J. F. Jr, Katona, I. M., Paul, W. E. \& Finkelman, F. D. Interleukin 4 is important in protective immunity to a gastrointestinal nematode infection in mice. Proc. Natl gastrointestinal nematode infection in 1.

71. Acad. Sci. USA 88, 5513-5517 (1991). bronchoalveolar T-lymphocyte population in atopic asthma. N. Engl. J. Med. 326, 298-304 (1992).

72. Ando, D. G., Clayton, J., Kono, D., Urban, J. L. \& Sercarz, E. E. Encephalitogenic T cells in the B10. PL model of experimental allergic encephalomyelitis (EAE) are of the $\mathrm{T}_{\mathrm{H}^{-1}} 1$ lymphokine subtype. Cell. Immunol. 124, are of the $T_{H^{-1}}$ lympt

73. Campbell, I. L., Kay, T. W., Oxbrow, L. \& Harrison, L. C. Essential role for interferon- $\gamma$ and interleukin- 6 in autoimmune insulin-dependent diabetes in NOD/Wehi mice. J. Clin. Invest. 87, 739-742 (1991).

74. Liew, F. Y. Functional heterogeneity of $\mathrm{CD} 4^{+} \mathrm{T}$ cells in leishmaniasis. Immunol. Today 10, 40-45 (1989).

75. Fong, T. A. \& Mosmann, T. R. Alloreactive murine CD $8^{+}$ $T$ cell clones secrete the $T_{H} 1$ pattern of cytokines. J. Immunol. 144, 1744-1752 (1990).
76. Ferrick, D. A. et al. Differential production of interferon- $\gamma$ and interleukin-4 in response to $T_{H} 1$ - and $T_{H} 2$-stimulating pathogens by $\gamma \delta \mathrm{T}$ cells in vivo. Nature $\mathbf{3 7 3}, 255-257$ (1995).

77. Peritt, D. et al. Differentiation of human NK cells into NK 1 and NK2 subsets. J. Immunol. 161, 5821-5824 (1998).

78. Chen, H. \& Paul, W. E. Cultured NK1.1+CD4+ T cells produce large amounts of IL-4 and IFN- $\gamma$ upon activation by anti-CD3 or CD1. J. Immunol. 159, 2240-2249 (1997).

79. Chen, Y., Kuchroo, V. K., Inobe, J., Hafler, D. A. \& Weiner, H. L. Regulatory T cell clones induced by oral tolerance: suppression of autoimmune encephalomyelitis. Science 265, 1237-1240 (1994)

80. Sakaguchi, S., Sakaguchi, N., Asano, M., Itoh, M. \& Toda, M. Immunologic self-tolerance maintained by activated T cells expressing $\mathrm{L}-2$ receptor $\alpha$-chain (CD25). Breakdown of a single mechanism of setf(CD25). Breakdown or a single mechanism of seltolerance causes various autoinmuned

81. Groux, H. et al. A CD4 $4^{+}$-cell subset inhibits antigenspecific T-cell responses and prevents colitis. Nature $\mathbf{3 8}$ 737-742 (1997).
Acknowledgements

I thank N. A. Mitchison, W. E. Paul and K. Vickerman for critcally reviewing the manuscript, and T. Mosmann, J. Lamb, S. Romagani, A. Fauci and H. Cantor for additional references. I am also grateful to $\mathrm{H}$. Arthur and B. Leung for help in research and X. Wei for graphics. The work was supported by research grants from the Medical Research Council and the Wellcome Trust.

\section{(2) Online links}

\section{Databases}

The following terms in this article are linked online to

LocusLink: http://www.ncbi.nlm.nih.gov/LocusLink/

CD4 | CD8 | CD80 | CD86 | c-Maf | Gata3 | GM-CSF | ICOS |

IFN- $\alpha$ | IFN- $\gamma$ | IgG1 | IgG2a | IL-1 | IL-2 | IL-3 | |L-4 | |L-5 | |L-12 |

Stat 4 |Stat6 | T-bet

\section{FURTHER INFORMATION}

Encyclopedia of Life Sciences: http://www.els.net

Hypersensitivity: T lymphocyte-mediating (type IV)

T lymphocytes: helpers

Access to this interactive links box is free online.

OPINION

\title{
A role for antigen in the maintenance of immunological memory
}

\section{David Gray}

The immune system has a memory that it exhibits in the enhanced and augmented responses the second time it meets an antigen. The memory is the result of a number of changes to the system brought about during the primary response. The most important of these changes is the formation of an expanded pool of antigenspecific memory cells. One of the enduring questions in immunology is how these memory cells are maintained for such long periods.

Until about 10 years ago, memory cells were thought to be very long-lived cells that required little, if any, external input to keep them alive. This view arose not out of data showing long cellular lifespans, but from the observation that memory responses could be elicited many years after immunization or infection. It has been a common failure in thinking about immunological memory to imbue the individual cells with properties of the whole system. Around 10-12 years ago, a number of studies were published that highlighted the influence of antigen on the survival of memory cells. These studies indicated that although the antigen-specific clones were long-lived, the constituent memory cells were relatively short-lived and required continued antigenic stimulation ${ }^{1-3}$. In the intervening period, the argument about antigen dependence has continued, and recent experiments have swung opinion back towards an antigenindependent view. In this article, I wish to argue that in reality, as opposed to experimental models, the role of antigen in memory maintenance is a very important one, and that antigen persistence might be a crucial asset for any vaccine.

\section{Antigen persistence and homeostasis} The idea of long-lived antigen-independent memory cells does not fit with certain properties of the immune system. First, the existence in lymphoid tissues of structures adapted for long-term maintenance of antigen; and second, the processes of homeostatic selection of the memory pool. Why is antigen stored in lymphoid tissues for many months and possibly years ${ }^{4}$ in the form of immune complexes, on the surface of follicular dendritic cells (FDCs)? A likely consequence of the persistence of antigen is the periodic stimulation of immune cells that causes their differentiation to effector cells, such as plasma cells (antibodysecreting cells) (FIG. 1a). Such stimulation could be necessary to maintain antigen-specific serum antibody at high levels for long periods - sometimes in excess of 20 years - as the plasma cells themselves are relatively shortlived. Interestingly, when wild-type memory 


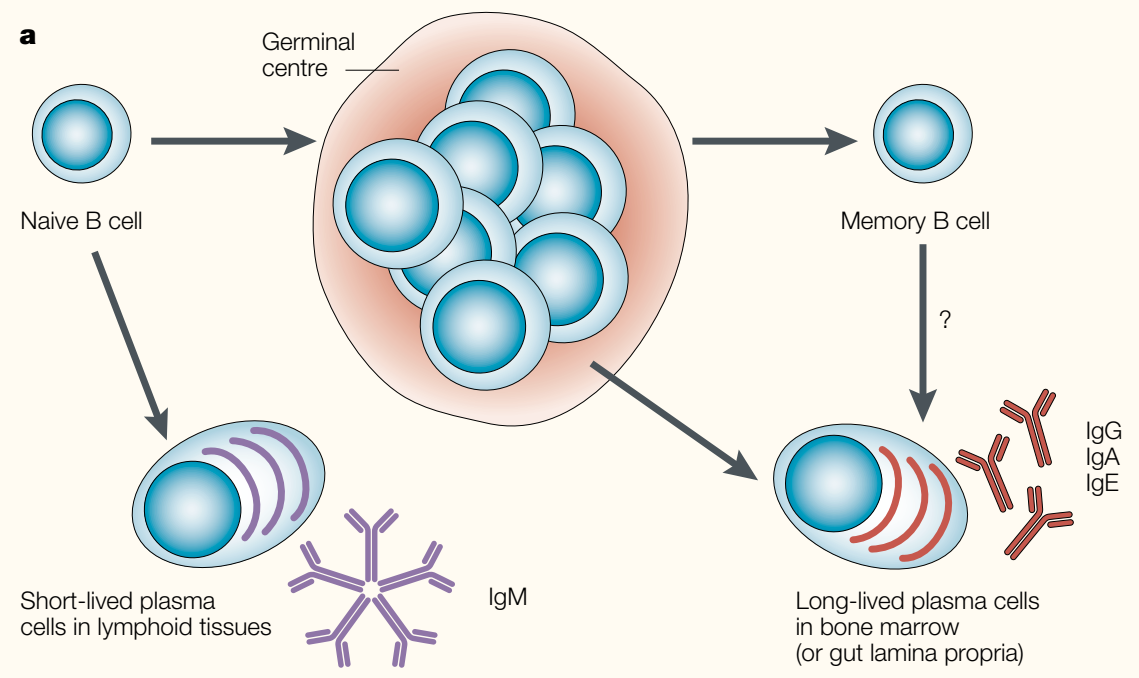

b

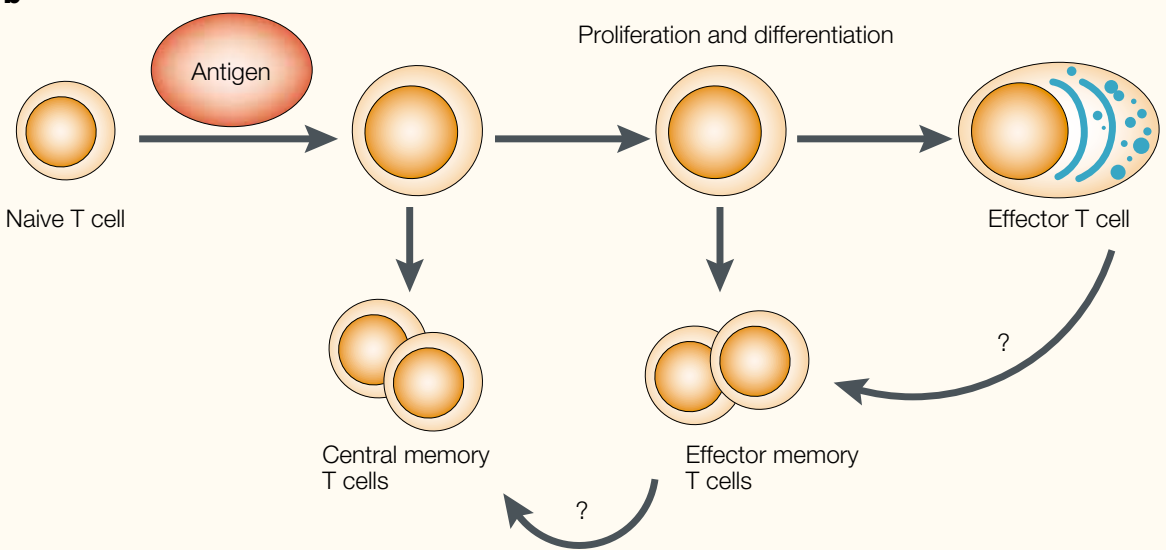

Figure 1 | Generation of memory cells and effector cells. a | Development of memory B cells and effector B cells (plasma cells) occurs in two phases. Short-lived plasma cells that make mostly lgM (but some lgG) are generated during the primary response and occupy sites, such as the splenic red pulp or lymph node medulla. B cells are also seeded to follicles to form germinal centres in this early phase. The second phase involves the formation of the memory B-cell pool and seeding of long-lived plasma cells to the bone marrow (making predominantly switched isotype antibodies). Plasma cells are terminally differentiated and do not give rise to memory cells. All arrows are driven by antigen and T-cell help. b | Development of memory T cells (CD4 and CD8). After activation, cells differentiate into effector T cells. Memory $T$ cells might be generated by divergence from this pathway or directly from effector $T$ cells ${ }^{17,50-52}$. There might be two subsets of memory cells ${ }^{53}$ : quiescent, central memory cells that recirculate from blood to secondary lymphoid organs, and effector memory cells that migrate through tissues ${ }^{54,55}$ and deliver a very rapid response on reactivation with antigen.

cells are transferred into lymphotoxin- $\alpha$ deficient mice, which lack FDCs, they fail to make a long-term immunoglobulin G response on stimulation ${ }^{5}$. Continuing antigenic stimulation of precursors (memory cells) to become plasma cells would very soon deplete the memory pool, and so it follows that memory cells must self-renew as a result of this stimulation. A direct prediction of this idea (unfortunately untested) is that within a short time of the serum antibody levels falling to zero, functional memory would also be lost. FDC-bound immune complexes are not the only examples of antigens that persist; many viruses remain in host tissues for years as a normal part of their life cycle ${ }^{6}$. Even those often assumed to be eliminated by the immune response (for example, lymphocytic choriomeningitis virus) have been shown to persist in a variety of forms ${ }^{7}$. One is left wondering if viruses are ever completely expelled by the immune response, and indeed, whether this would be an entirely wise strategy, as memory and protective immunity are perpetuated by antigen. Parasitic infections, of which malaria is a prime example, can also be controlled at asymptomatic levels for years $^{8}$. These examples indicate that the period over which antigen can influence the immune response is very long.

New memory cells are generated throughout life; however, the memory pool, like all lymphocyte populations, is finite in size $e^{9,10}$. A process of homeostasis must operate to regulate the survival and/or the deletion of memory cells. What happens when new memory cells are generated? Current evidence indicates that pre-existing memory cells are deleted in a process that has been termed 'attrition' ${ }^{11}$, and represents homeostatic deletion (FIG. 2a). Which memory cells are deleted and why is, at present, unclear. However, maintaining the cells that have been activated by antigen in the recent past would ensure responsiveness to antigens that have shown themselves to be in the immediate environment. One way to bring this about would be to use FDC antigen depots to keep at least a proportion of a memory clone in an active state. In this state, memory cells might continue to cycle or retain the capacity to respond to survival signals. For some memory cells (for example, mouse CD8 memory $\mathrm{T}$ cells) there might be a surrogate for antigen in the form of a cytokine that is released by tissue cells on infection. So, interferon (IFN)- $\alpha / \beta$ made by virally infected cells causes a limited proliferation of memory phenotype CD8 T cells ${ }^{12}$. In fact, IFN- $\alpha / \beta$ induces interleukin (IL)-15 production by DCs and macrophages ${ }^{13,14}$, and it is this cytokine that acts on memory-type CD8 T cells to elicit cell division ${ }^{9,13}$. Both IL-15- and IL-15 receptor- $\alpha$ (IL-15R $\alpha$ )-chain knockout mice exhibit selective deficiencies in memory CD8 T cells ${ }^{15,16}$. This IL-15-driven proliferation of CD8 memory cells might balance homeostatic deletion that occurs in a different part of the same clone. In this way, IL-15 maintains memory cells that remain in a semi-activated state and continue to express IL-15R $\mathrm{R}^{15,16}$, allowing the CD8 T-cell population to sample the external environment for virological challenge. To work as a means of memory-cell homeostasis, IL-15R expression (probably the IL-2R $\beta$-chain; CD $122^{13}$ ) should be heterogeneous within a clone, being downregulated with time after activation; cells that lack the receptor becoming susceptible to deletion (FIG. 2b). Maintenance or upregulation of the receptor could be achieved by antigen stimulation; at present, the stability of expression of IL-15R following antigenic stimulation is not known.

\section{Lessons from vaccination?}

Before I discuss the experiments that attempt to test antigen-dependence of memory, it is worth considering the experience 
a

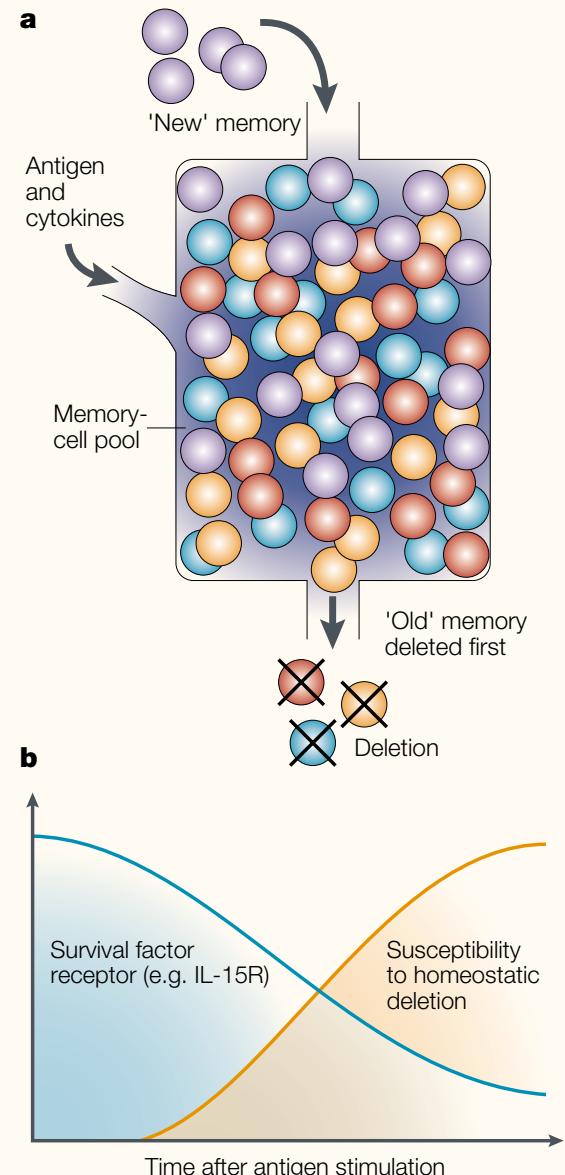

Figure 2 | Model of homeostasis in the memory pool. a | For each new memory cell that is generated, one must be deleted. This should be on the basis of their ability to access or respond to survival factors, such as antigen or cytokines, both of which replenish the memory pool and can balance homeostatic deletion. $\mathbf{b} \mid$ A simple model of how this might work is suggested: the expression of receptors for the survival factor (for example, IL-15 receptor; IL-15R) decays over time after antigen stimulation. So, the longer the time from encounter with antigen, the more likely the cells will be lost from the system.

of vaccination. Examples of long-term responses and memory following infection or vaccination are often quoted in support of antigen independence; however, the information is generally incomplete. For instance, the famous example of the measles outbreak in the isolated community of the Faroe Islands, where immunity to the virus survived 65 years between epidemics, is not, as often cited, an example of an antigen-independent mechanism ${ }^{17}$. It is clearly evidence against re-exposure as a necessity for memory survival, but measles virus can persist in the brain and might be re-activated much later to cause subacute sclerosing panencephalitis ${ }^{6}$, and so this is not strictly evidence for antigen-free survival of memory. A better example for antigen-independent survival is the case of six people in Virginia, USA, who, 75 years after an attack of yellow fever, were found to have circulating antibodies to the yellow fever virus ${ }^{18}$. This virus is thought to be completely eliminated by the immune response, although the longevity of the response leads me to doubt this. The detection of serum antibody for 25 or 30 years after vaccination with non-replicating vaccine preparations, such as tetanus or diphtheria toxoid, is well documented. Such long-lived antibody responses are only apparent if the individuals were given at least two booster injections in the first year after vaccination ${ }^{17}$. This could mean that crucial levels of antibody-antigen complex must accumulate on the FDC for antibodies (and memory) to be maintained for 30 years. Alternatively, the booster injections might increase the plasma cell population size to an extent that will be functionally relevant over this extended period. The timescale makes both of these proposals seem a little farfetched: can antigen really persist on FDCs for 30 years? And can plasma cells really survive and secrete antibody for 30 years? We do not know how long FDCs or plasma cells remain alive and functionally active in humans. In mice, FDCs seem to survive for the lifetime of the mouse (indicated by detection of antigen-antibody complexes in situ 18 months after injection of antigen; D. G. and M. Kosco-Vilbois, unpublished observations). Plasma cells in the mouse bone marrow (the main source of circulating antibodies) have an estimated half-life of 5 months ${ }^{19}$; no estimates are available in humans. It is unclear if it is appropriate to extrapolate these figures 40 -fold when considering the lifespan of the human equivalents (on average we live 40-times longer than a mouse). If neither long-lived FDCs nor long-lived plasma cells are conceivable, then we must resort to re-exposure to the same or crossreacting organisms to explain such long-lived antibody responses

More generally, it is the common experience of vaccination that live, attenuated viral vaccines are much more efficient than killed viral vaccines or non-replicating recombinant vaccines at eliciting long-term protection ${ }^{6}$. Again, this can be interpreted quantitatively - replicating viruses generate a much higher antigen load to be deposited on FDCs or to expand the memory pool. However, there might also be a qualitative aspect to this, with the inflammatory cytokines associated with the antiviral response pushing the cells to become effector cells, such as long-lived plasma cells. A good example of this is provided by a recent study of the differing responses to live or heat-killed Listeria monocytogenes: heat-killed bacteria generated high frequencies of CD8 memory cells but no protective response, in contrast to the live Listeria, which gave rise to both ${ }^{20}$.

This brief discussion illustrates an urgent need for more studies on the interaction of different antigenic formulations (for example, live versus non-replicating vaccines) with the immune system. In relation to antigen dose, there are arguments against large singleantigen doses or complex mixtures of antigen (especially peptides), to avoid clonal exhaustion $^{21,22}$ and clonal competition ${ }^{23,24}$, respectively. However, these caveats apply to initial antigen dose and not to antigen persistence. Leaving aside chronic infection, which indicates that responses are impaired, there is no data to indicate that antigen persisting in the body is anything but a good thing. The notion that antigen persistence is something to be avoided, as some experimental immunologists have suggested ${ }^{25}$, does not take into account the real immune system and the need for protection.

\section{Memory maintenance in experiments}

Experimentally, the absolute requirement for antigen to maintain memory is still controversial. However, the notion that memory cells exist in a long-term G0 resting state is no longer tenable 9 . The current consensus is that even in situations in which there is no selective pressure and no antigen, memory cells remain in a 'semi-activated' state, owing to stimulation by cytokines (for CD8 memory cells) ${ }^{13}$ or by 'tickling' of the T-cell receptor by major histocompatibility complex (MHC)-peptide complexes ${ }^{26}$. As with most cells of the body, apoptosis might be a default fate, which is staved off by microenvironmental signals ${ }^{27}$. Therefore, lymphocytes are sustained only if microenvironmental resources are available ${ }^{28}$ or, in other words, only if there are niches to $\operatorname{occupy}^{10}$ (FIG. 3a). The ecological analogy is a useful one: different types of lymphocyte occupy different niches, most obviously B cells and T cells. But so too do naive and memory $\mathrm{T}$ cells ${ }^{10}$, the former requiring $\mathrm{MHC} /$ dendritic cell contact ${ }^{26}$ and the latter being less dependent on MHC but relying on cytokines ${ }^{12}$ (FIG. 3b). The lymphoid system, like any environment, has a finite number of niches, and in a normal system that is full of lymphocytes there is constant competition for the resources. When new memory cells are generated, similar numbers are deleted (homeostasis) (FIG. 2). The only way to understand factors that influence the survival of memory cells is to study them in their natural habitat. 
a

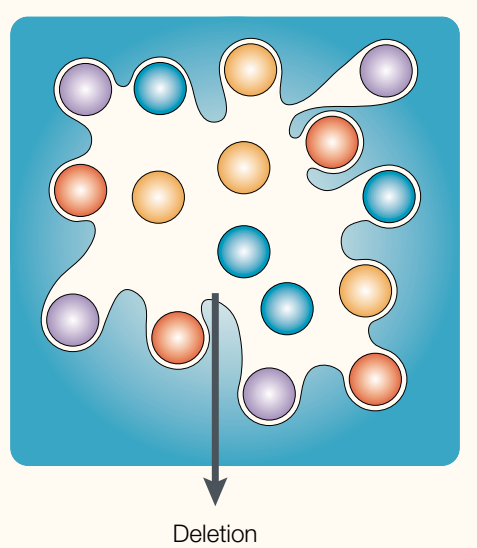

b

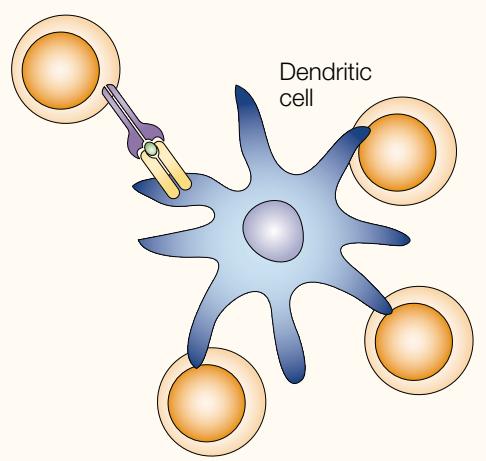

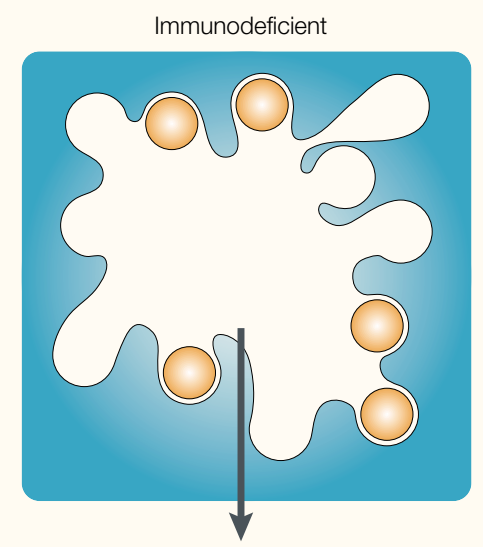

Extended survival

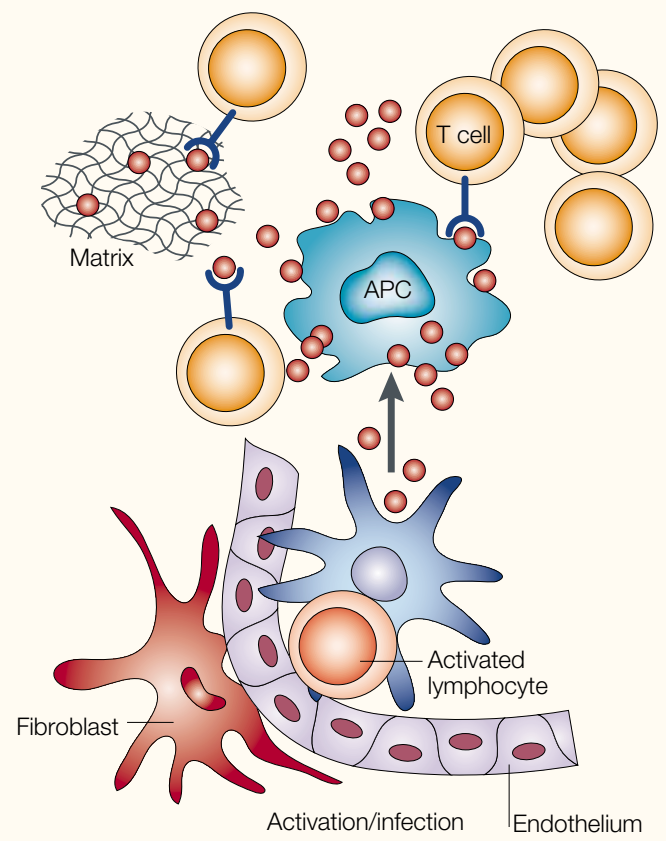

Figure 3 | Niche occupancy in different lymphoid systems. a | Occupancy of niches in a normal (full) immune system and an experimental (immunodeficient) immune system. Pockets represent niches, the identity of which is depicted (speculatively) in part b. The right-hand panel (immunodeficient system) is a representation of memory experiments in which memory T cells from T-cell receptor transgenic mice are transferred in small numbers to immunodeficient $\left(R a g 1^{1--}\right.$ or $\mathrm{MHC}^{--}$) mice. In this system the cells have no competition, whereas if the transfer was done into irradiated mice, host cells from bone marrow and thymus would eventually repopulate and compete for niches. $\mathbf{b}$ | Possible identity of niches/resources needed by lymphocytes for their survival. Available data indicate that naive $T$ cells require contact with MHC, whereas memory cells are less dependent on this, but more reliant on cytokines (for a review, see REF. 56). The source of MHC class II as a maintenance signal is likely to be dendritic cells ${ }^{57}$. Dendritic cells or macrophages also make cytokines, such as interleukin-15, but cytokines are likely to be produced by a wide range of tissue cells (for example, type 1 interferons) after activation or infection. APC, antigenpresenting cell; MHC, major histocompatibility complex; Rag1, recombination-activating gene 1.

Most, but not all ${ }^{29,30}$, studies over the past 5-10 years that have addressed memory-cell survival have used slightly artificial model systems, using T-cell receptor transgenic mice. Memory cells are generated in vivo, and then transferred into adoptive hosts that are T-cell deficient and are unable to repopulate from bone marrow or thymus (BOX 1). From this type of experiment, it has been concluded that memory $\mathrm{T}$ cells survive for long periods in

the absence of antigen ${ }^{25,26,31-34}$ and often without access to MHC molecules ${ }^{25,26,33,34}$. In my opinion, it would be more accurate to conclude that, in the absence of competition, memory cells can survive indefinitely. In immunodeficient mice, the number of niches is effectively unlimited, and the transferred cells could survive significantly longer than physiologically normal (FIG. 3) for two possible reasons: first, competition for access to survival factors, such as cytokines, is removed (at least temporarily); and second, because the 'homeostatic proliferation' that occurs after transfer to immunodeficient hosts (presumably MHC or cytokine driven ${ }^{35,36}$ ) expands the input population. Our own experience, with $\mathrm{B}$ cells and $\mathrm{CD} 4^{+} \mathrm{T}$ cells, is that when memory cells are transferred (at physiological frequencies) into hosts capable of repopulation from primary lymphoid tissues, they fall to undetectable levels within a matter of weeks if antigen is not present ${ }^{1,2,37}$, and the same is true in intact mice ${ }^{38}$.

The most elegant experiment, so far, to test the absolute requirement for antigen did so by changing the specificity of memory B cells by Cre/Lox recombination (deleting one $\mathrm{V}_{\mathrm{H}}$, gene, while inverting another $)^{39}$. Over the time studied (15 weeks), memory cells generated against nitrophenyl (NP) were maintained with little decay, even though they now possessed a receptor that bound phycoerythrin (PE) and not NP. Despite the elegance of the experimental design, a number of uncertainties exist; for instance, the possibility of crossreactivity of the new receptor, and the fact that it is difficult to draw strong conclusions about the decay of the PE-specific memory cells when so few cells are analysed. Competition arguments are also still pertinent: mice maintain their pool of $\lambda$-light-chain-expressing cells and antibodies at around $5 \%$; in these mice all the $\lambda$-positive cells are PE binding, carrying a single $\mathrm{V}_{\mathrm{H}}$ and so might avoid normal homeostatic mechanisms based on $\mathrm{V}_{\mathrm{H}}$ expression (in other words, antigen specificity) $)^{40-42}$. In addition, and most importantly, the survival of the PE-binding cells needs to be assayed over a longer period and also in the face of competition from newly generated memory cells (in comparison with NP-specific cells). Experiments by Maruyama, Lam and Rajewsky ${ }^{39}$, however, might well indicate that antigen persistence is not an absolute requirement for memorycell survival. Does this mean that antigen is unimportant for long-term memory-cell survival? Far from it. Homeostatic selection means that any memory cell with a readily, if intermittently, available source of antigen will have a clear selective advantage over one that does not. Antigen does persist in the immune system for a very long time after immunization or infection, and during this time it can, and does, influence antigenspecific lymphocytes. Although memory might not, in experimental terms, be absolutely dependent on antigen, it is strongly potentiated by it, and in the normal, intact immune system, antigen protects the memorycell population from terminal attrition. 


\section{Box 1 | Experiments to assay memory-cell survival}

The classical assay for memory cells is adoptive transfer of lymphocytes from antigen-primed mice into sub-lethally irradiated recipients (a). In such mice, not all host lymphocytes are killed and repopulation occurs from bone marrow and thymus. The readout of such an experiment is normally functional; for example, the ability of the transferred cells to mount an enhanced response in comparison to transferred naive cells (for example, antibody production, proliferation or cytokine production after in vitro restimulation). Donor cells are often recognized with antibodies to an allotypic marker (for example, IgH, Igא, Thyl and Ly5). Memory cells generally need reactivation (boosting in vivo) to detect their response ex vivo (compare with effector cells; $\mathrm{BOX} 2$ ). An alternative to adoptive transfer is limiting dilution analysis to measure the frequency of antigen-specific memory cells after immunization of intact mice (this requires in vitro restimulation and culture 7 days or more; gives frequencies that are severalfold lower than tetramers and so might not provide optimal conditions for assaying all memory cells). More recently, a new type of adoptive transfer has been developed using gene-targeted mice as recipients and transgenic mice as donors $(\mathbf{b})$. Therefore, antigen-primed lymphocytes or activated cells from T-cell receptor transgenic mice are transferred into immunodeficient mice (severe combined immunodeficiency, scid; recombination-activating gene, $\mathrm{Rag}^{-1-}$; or major histocompatibility complex, $\mathrm{MHC}^{-1}$ ). The readout in these experiments is usually enumeration of cells surviving after weeks or months, measured by clonotypic antibody, but, in addition, might include in vivo or in vitro assessment of functional activity (proliferation and cytotoxicity) after reactivation. Potentially, the method of choice is to follow antigen-specific cells without having to perform adoptive transfer with all its attendant artefacts. For B cells, it has been possible for some time to measure antigen-specific cells by flow cytometry (and immunohistology) using fluorescent antigens ${ }^{47}$, but for $\mathrm{T}$ cells this has only recently become available with the advent of MHC tetramers ${ }^{48}(\mathrm{c})$. Although this is a very powerful technique, it needs to be combined with full analysis of other phenotypic markers (for instance, to distinguish memory from effector cells). Moreover, few studies have attempted to correlate tetramer-positive $\mathrm{T}$ cells with memory function this needs to be addressed.

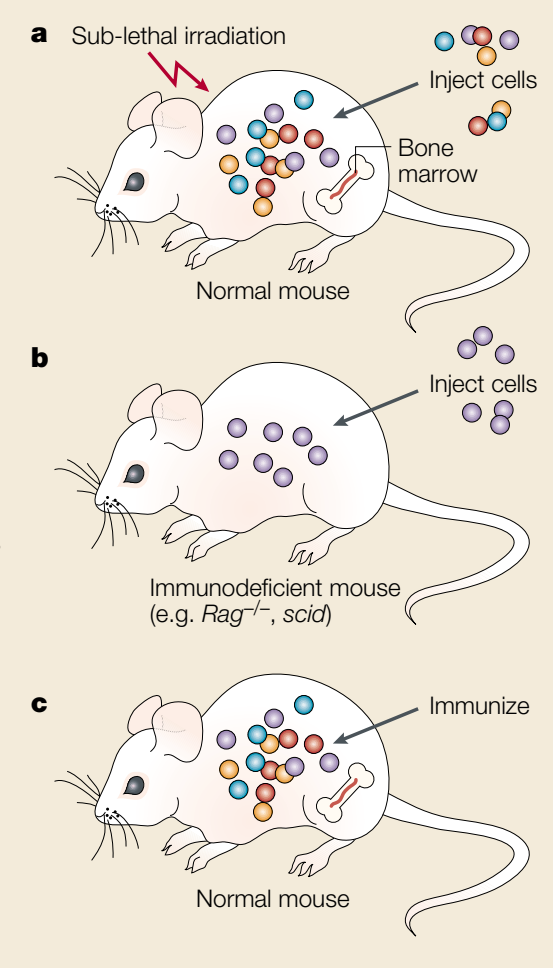

\section{Concluding remarks}

So far, we have focused on the arguments and experiments of immunologists who are trying to understand memory. A nonimmunologist would surely understand immunological memory as the means of vaccine-mediated protection from infectious disease. Immunologists, as expected, have more sophisticated and more varied definitions that are based on experimental constructs. Our basic methodology is the detection in the immune system of increased numbers of antigen-specific lymphocytes that is, memory cells. Memory cells, under certain circumstances, might deliver protection from reinfection, but they provide no guarantee ${ }^{17,43}$. It is effector cells and their products that most reliably deliver protective immunity (see BOX 1 and BOX 2 for a discussion of the measurement of memory and effector cells, respectively). These can be plasma cells making serum or mucosal antibodies, or cytotoxic $\mathrm{T}$ cells that kill virusinfected cells cytokine-secreting $\mathrm{T}$ cells that activate macrophages. They efficiently protect, because they actively secrete molecules that provide a barrier to reinfection (for example, antibodies) or they can be rapidly triggered to respond (for example, to kill) (FIG. 1). Evidence indicates that to keep effector cells in this heightened state of readiness or activity requires the continued presence of antigen $^{44-46}$ (also see BOX 2). Furthermore, memory cells that survive for long periods in immunodeficient hosts, in the absence of MHC (see above), show impaired functional activity (B. Stockinger, personal communication). For this reason alone, in my view, it would be a foolhardy immunologist who designed a vaccine that did not persist in some form and did not interact with the key cellular component of memory response, the FDC.

David Gray is in the Institute of Cell, Animal and Population Biology, University of Edinburgh, Ashworth Laboratories, King's Buildings, West Mains Road, Edinburgh EH9 3JT, UK. e-mail: d.gray@ed.ac.uk DOI: 10.1038/nri706

\section{Box 2 | Assays of effector cells and their lifespan}

Unlike memory cells, effector cells provide a measure of their presence or activity directly ex vivo and no (or very short) in vitro culture need be carried out to reveal this. For plasma cells, it can be a simple matter of obtaining serum and assaying for antibodies that bind to the immunizing antigen. To enumerate the effector cells from tissues, one can use FACS (fluorescent-activated cell sorting) to stain for intracellular antibodies (plasma cells) or cytokines (effector T cells). Also, ELISPOT (enzyme-linked immunospot) methods (for cytokines or antigen-specific antibodies; capture, on a solid phase, of soluble molecules secreted from single cells, which are then developed and counted as coloured spots) can be used to enumerate effector cells. Both methods rely on an increase above non-immunized controls to measure the antigen-specific response.

There is some controversy about the lifespan and antigen-dependence of plasma cells. On the one hand, Slifka et al. ${ }^{19}$ and Manz et al. ${ }^{49}$ show long-term antigen-independent survival of specific antibody production after adoptive transfer. On the other hand, Zinkernagel and colleagues ${ }^{45}$ show that long-term protective antibody responses are dependent on the continued presence of antigen, CD4 T-cell help and proper lymphoid organ structure - all factors pointing to a role for re-stimulation of memory precursors by antigen on FDCs. The difference between the two camps might lie in the way in which they measure the antibody response. Slifka et al. ${ }^{19}$ and Manz et al. ${ }^{49}$ measure the specific serum antibody by ELISA or ELISPOT, both methods that rely on binding antigen to the solid phase and as such detect both high- and low-affinity antibodies $\left(>10^{6} \mathrm{M}^{-1}\right)$. Ochsenbein et al $^{45}$ measure antibodies that neutralize the immunizing virus, a process that requires affinities of $>10^{8} \mathrm{M}^{-1}$. 
1. Gray, D. \& Skarvall, H. B cell memory is short-lived in the absence of antigen. Nature 336, 70-73 (1988).

2. Gray, D. \& Matzinger, P. T cell memory is short-lived in the absence of antigen. J. Exp. Med. 174, 969-974 (1991).

3. Oehen, S., Waldner, H., Kündig, T. M., Hengartner, H. \& Zinkernagel, R. M. Antivirally protective cytotoxic T cell memory to lymphocytic choriomeningitis virus is governed by persisting antigen. J. Exp. Med. 176 governed by persisting

4. Tew, J. G. \& Mandel, T. E. Prolonged antigen half-life in the lymphoid follicles of specifically immunized mice. Immunology 37, 69-76 (1979).

5. Fu, Y. X., Huang, G., Wang, Y. \& Chaplin, D. D. Lymphotoxin- $\alpha$-dependent spleen microenvironment supports the generation of memory B cells and is required for their subsequent antigen-induced activation. J. Immunol. 164, 2508-2514 (2000).

6. Mims, C. A., Nash, A. \& Stephen, J. Pathogenesis of Infectious Disease (Academic, London, 2000).

7. Ciurea, A. et al. Persistence of lymphocytic choriomeningitis virus at very low levels in immune mice. Proc. Natl Acad. Sci. USA 96, 11964-11969 (1999).

8. Hamad, A. A. et al. Chronic Plasmodium falciparum infections under low intensity malaria transmission in the Sudan. Parasitology 120, 447-456 (2000).

9. Marrack, P. et al. Homeostasis of $\alpha \beta \mathrm{TCR}^{+} \mathrm{T}$ cells. Nature Immunol. 1, 107-111 (2000).

10. Freitas, A. A. \& Rocha, B. Population biology of Iymphocytes: the flight for survival. Annu. Rev. Immunol. 18, 83-111 (2000).

11. Selin, L. K. et al. Attrition of T cell memory: selective loss of LCMV epitope-specific memory CD8 T cells following infections with heterologous viruses. Immunity $\mathbf{1 1}$, 733-742 (1999).

12. Tough, D. F., Borrow, P. \& Sprent, J. Induction of bystander $\mathrm{T}$ cell proliferation by viruses and type I interferon in vivo. Science 272, 1947-1950 (1996).

13. Zhang, X., Sun, S., Hwang, I., Tough, D. \& Sprent, J. Potent and selective stimulation of memory-phenotype CD8 ${ }^{+} \mathrm{T}$ cells in vivo by IL-15. Immunity 8, 591-599 (1998).

14. Mattei, F., Schiavoni, G., Belardelli, F. \& Tough, D. F. $\mathrm{IL}-15$ is expressed by dendritic cells in response to type I IFN, double-stranded RNA, or lipopolysaccharide and promotes dendritic cell activation. J. Immunol. 167. 1179-1187 (2001).

15. Lodolce, J. P. et al. IL-15 receptor maintains lymphoid homeostasis by supporting lymphocyte homing and proliferation. Immunity 9, 669-676 (1998).

16. Kennedy, M. K. et al. Reversible defects in natural killer and memory CD8 T cell lineages in interleukin 15-deficient mice. J. Exp. Med. 191, 771-780 (2000).

17. Ahmed, R. \& Gray, D. Immunological memory and protective immunity: understanding their relation. Science 272, 54-60 (1996).

18. Mims, C. A. Pathogenesis of Infectious Disease 3rd edn (Academic, London, 1987)

19. Slifka, M. K. Antia, R. Whitmire, J. K. \& Ahmed, R. Humoral immunity due to long-lived plasma cells. Immunity 8, 363-372 (1998).

20. Lauvau, G. et al. Priming of memory but not effector CD8 T cells by a killed bacterial vaccine. Science $\mathbf{2 9 4}$, 1735-1739 (2001).

21. Sercarz, E. E. et al. Dominance and crypticity of T cell antigenic determinants. Annu. Rev. Immunol. 11, 729-766 (1993).

22. Chen, W., Anton, L. C., Bennink, J. R. \& Yewdell, J. W. Dissecting the multifactorial causes of immunodominance in class I-restricted T cell responses to viruses. Immunity 12, 83-93 (2000).

23. Moskophidis, D., Lechner, F., Pircher, H. \& Zinkernagel, R. M. Virus persistence in acutely infected immunocompetent mice by exhaustion of antiviral cytotoxic effector T cells. Nature 362, 758-761 (1993).

24. Gallimore, A. et al. Induction and exhaustion of lymphocytic choriomeningitis virus-specific cytotoxic T lymphocytes visualized using soluble tetrameric major histocompatibility complex class I-peptide complexes. histocompatibility complex class I-peptide . . 187, 1383-1393 (1998).

25. Swain, S. L., Hu, H. \& Huston, G. Class II-independent generation of CD4 memory T cells from effectors. generation of CD4 memory T cells
Science 286, 1381-1383 (1999).

26. Tanchot, C., Lemonnier, F. A., Perarnau, B., Freitas, A. A \& Rocha, B. Differential requirements for survival and proliferation of CD8 naive or memory T cells. Science 276, 2057-2062 (1997).

27. Raff, M. C. Social controls on cell survival and cell death Nature 356, 397-400 (1992).

28. McLean, A. R., Rosado, M. M., Agenes, F., Vasconcellos, R. \& Freitas, A. A. Resource competition as a mechanism for B cell homeostasis. Proc. Natl Acad. Sci. USA 94 5792-5797 (1997).

29. Lau, L. L., Jamieson, B. D., Somasundaram, T. \& Ahmed, R. Cytotoxic T-cell memory without antigen. Nature 369, 648-652 (1994).

30. Hou, S., Hyland, L., Ryan, K. W., Portner, A. \& Doherty P. C. Virus-specific CD8 ${ }^{+}$T-cell memory determined by clonal burst size. Nature 369, 652-654 (1994).

31. Bruno, L., Kirberg, J. \& von Boehmer, H. On the cellular basis of immunological T cell memory. Immunity 2, 37-43 (1995).

32. Markiewicz, M. A. et al. Long-term T cell memory requires the surface expression of self- peptide/major histocompatibility complex molecules. Proc. Natl Acad. Sci. USA 95, 3065-3070 (1998).

33. Murali-Krishna, K. et al. Persistence of memory CD8 T cells in MHC class I-deficient mice. Science $\mathbf{2 8 6}$, 1377-1381 (1999).

34. Garcia, S., DiSanto, J. \& Stockinger, B. Following the development of a CD4 T cell response in vivo: from activation to memory formation. Immunity 11, 163-171 (1999).

35. Ernst, B., Lee, D. S., Chang, J. M., Sprent, J. \& Surh, C. D. The peptide ligands mediating positive selection in the thymus control T cell survival and homeostatic proliferation in the periphery. Immunity 11, 173-181 (1999).

36. Tan, J. T. et al. IL-7 is critical for homeostatic proliferation and survival of naive T cells. Proc. Natl Acad. Sci. USA 98, 8732-8737 (2001)

37. van Essen, D., Dullforce, P., Brocker, T. \& Gray, D. Cellular interactions involved in $T_{H}$ memory. J. Immunol. 165 3640-3646 (2000)

38. Colle, J. H., Truffa-Bachi, P. \& Freitas, A. A. Secondary antibody responses to thymus-independent antigens. Decline and life-span of memory. Eur. J. Immunol. 18, 1307-1314 (1998).

39. Maruyama, M., Lam, K. P. \& Rajewsky, K. Memory B-ce persistence is independent of persisting immunizing antigen. Nature 407, 636-642 (2000).

40. Gu, H., Tarlinton, D., Muller, W., Rajewsky, K. \& Forster, I. Most peripheral $B$ cells in mice are ligand selected. J. Exp. Med. 173, 1357-1371 (1991).

41. Viale, A. C., Coutinho, A., Heyman, R. A. \& Freitas, A. A. $\checkmark$ region dependent selection of persistent resting $\checkmark$ region dependent selection of persistent resting 5. 599-605 (1993).
42. Rosado, M. M. \& Freitas, A. A. The role of the B cell receptor $\vee$ region in peripheral B cell survival. Eur. $J$. Immunol. 28, 2685-2693 (1998).

43. Zinkernagel, R. M. et al. On immunological memory. Annu. Rev. Immunol. 14, 333-367 (1996).

44. Kundig, T. M. et al. On the role of antigen in maintaining cytotoxic T-cell memory. Proc. Natl Acad. Sci. USA 93 9716-9723 (1996).

45. Ochsenbein, A. F. et al. Protective long-term antibody memory by antigen-driven and T helper-dependent differentiation of long-lived memory B cells to short-lived plasma cells independent of secondary lymphoid organs. Proc. Natl Acad. Sci. USA 97, 13263-13268 (2000).

46. Ochsenbein, A. F. et al. A comparison of T cell memory against the same antigen induced by virus versus intracellular bacteria. Proc. Natl Acad. Sci. USA 96 9293-9298 (1999)

47. Schittek, B. \& Rajewsky, K. Maintenance of B-cell memory by long-lived cells generated from proliferating precursors. Nature 346, 749-751 (1990).

48. Altman, J. D. et al. Phenotypic analysis of antigenspecific T lymphocytes. Science 274, 94-96 (1996)

49. Manz, R. A., Lohning, M., Cassese, G., Thiel, A. \& Radbruch, A. Survival of long-lived plasma cells is independent of antigen. Int. Immunol. 10, 1703-1711 (1998).

50. Jacob, J. \& Baltimore, D. Modelling T-cell memory by genetic marking of memory T cells in vivo. Nature $\mathbf{3 9 9}$ 593-597 (1999).

51. Opferman, J. T., Ober, B. T. \& Ashton-Rickardt, P. G. Linear differentiation of cytotoxic effectors into memon Tlymphocytes. Science 283, 1745-1748 (1999).

52. Lanzavecchia, A. \& Sallusto, F. Dynamics of $T$ lymphocyte responses: intermediates, effectors, and memory cells. Science 290, 92-97 (2000).

53. Sallusto, F., Lenig, D., Forster, R., Lipp, M. \& Lanzavecchia, A. Two subsets of memory T lymphocytes with distinct homing potentials and effector functions. Nature 401, 708-712 (1999).

54. Masopust, D., Vezys, V., Marzo, A. L. \& Lefrancois, L. Preferential localization of effector memory cells in nonlymphoid tissue. Science 291, 2413-2417 (2001).

55. Reinhardt, R. L., Khoruts, A., Merica, R., Zell, T. \& Jenkins, M. K. Visualizing the generation of memory CD4 T cells in the whole body. Nature 410, 101-105 (2001).

56. Goldrath, A. W. \& Bevan, M. J. Selecting and maintaining a diverse T-cell repertoire. Nature 402, 255-262 (1999).

57. Brocker, T. Survival of mature CD4 T lymphocytes is dependent on major histocompatibility complex class II-expressing dendritic cells. J. Exp. Med. 186 1223-1232 (1997)

\section{(4) Online links}

\section{DATABASES}

The following terms in this article are linked online to: LocusLink: http://www.ncbi.nlm.nih.gov/LocusLink

CD122 | IL-15 | IL-15R $\alpha$ | lymphotoxin- $\alpha$ | Rag1 | scid | Thy

\section{FURTHER INFORMATION}

David Gray's lab: http://helios.bto.ed.ac.uk/icapb/people/ d_gray.html

Encyclopedia of Life Sciences: http:www.els.net follicular dendritic cells (B lymphocyte stimulating) |

immunological memory 